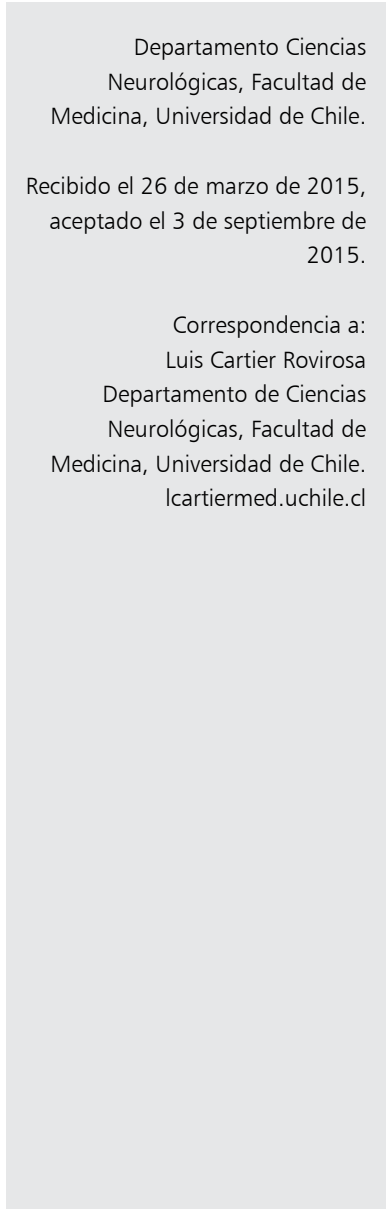

\section{Leucoencefalopatía tóxica fatal: tres casos asociados al consumo de pasta base de cocaína}

\author{
LUIS CARTIER R., DANIELA GONZÁLEZ L., JORGE HARÁN D.
}

\begin{abstract}
The prevalence of drug-associated toxic encephalopathy is unknown, but it is an uncommon condition. Toxic leukoencephalopathy was described associated with heroin consumption, it has been less commonly described with the use of cocaine and there are no reports of its association with consumption pasta base of cocaine (PBC). We report two females aged 31 years and a male aged 19 years, consumers of $P B C$ who developed a fatal toxic leukoencephalopathy. They initiated their disease with severe and persistent headache, sequential focal neurologic deficits and a progressive impairment of consciousness that culminated with their death. Laboratory parameters such as blood count, cerebrospinal fluid analyses or infectious biological indices were normal. MRI showed multifocal lesions in brain white matter of both hemispheres confirming the leukoencephalopathy. There was no response to the use of methylprednisolone.
\end{abstract}

(Rev Med Chile 2015; 143: 1484-1489) brain.

Key words: Cocaine; Leukpencephalopaties; Spongy degeneration of the
$\mathrm{V}$ ariadas alteraciones del Sistema Nervioso Central (SNC) se han descrito en relación al consumo de substancias adictivas como heroína, cocaína y drogas "de autor "1. Sin embargo, la leucoencefalopatía tóxica fatal, siendo una patología de excepción, es de especial interés por su gravedad. En 1982 Wolters y colaboradores la identificaron en relación a la inhalación de heroí$\mathrm{na}^{2}$, seguidamente otros autores al uso de heroína intravenosa ${ }^{3}$, de cocaína $^{4}$ y de otras drogas ${ }^{5,6}$. La leucoencefalopatía tóxica es una entidad que está bien definida ${ }^{7}$. Se ha descrito un comienzo agudo con apatía, bradifrenia, compromiso progresivo de conciencia, ataxia, paresias, plejias, alteraciones del lenguaje, pérdidas de visión, mioclonías, espasmos, fiebre de origen central, pudiendo llegar a la muerte ${ }^{4,7,8}$. En la resonancia magnética (RM) se identifican hiperintensidades difusas o multifocales en T2 y FLAIR en ambos hemisferios cerebrales ${ }^{9-11}$. En el estudio neuropatológico se observa una degeneración espongiforme de la mielina, expresión de un daño selectivo de axones del centro oval, que hace contraste con la preservación de las fibras subcorticales en $\mathrm{U}^{10}$.

Este daño no está originado por la repetición del consumo, ni es debido a la acumulación tóxica del estupefaciente, sino que es una expresión idiosincrática relacionada al último consumo, respuesta no convencional que avala el desarrollo de leucoencefalopatías relacionadas a una primera y única ingestión de droga ${ }^{12,13}$. En estos casos excepcionales debiera ponderarse la posible presencia de aditivos tóxicos en la droga usada ${ }^{4}$.

En Chile, la cocaína es la segunda droga ilegal de mayor consumo. Su uso alcanza una prevalencia anual de 1,9\%. Para clorhidrato de cocaína 
(CC) es de $1,28 \%$ y para pasta base de cocaína (PBC) de 0,62\%. La PBC es una forma menos purificada de la droga, integrada fundamentalmente por sulfato de cocaína y aditivos ${ }^{14}$. El CC y la PBC producen efectos psicotrópicos $y$, aunque puedan producir algún compromiso neurotóxico, el daño más frecuente recae sobre el sistema vascular, generando hipertensión, vasoespasmos y vasculitis, alteraciones que propician accidentes cerebrovasculares $^{15}$. A ello se puede agregar hipoxias, producto de eventuales colapsos cardiopulmonares que sufren los intoxicados.

Esta leucoencefalopatía tóxica tienen una latencia de varios días entre ingesta y síntomas que puede hacer olvidar su origen, creando confusión en su diagnóstico con leucoencefalopatías autoinmunes como encefalomielitis aguda diseminada (ADEM), esclerosis múltiple tumefacta (variantes de Marburg o Balo), leucoencefalitis aguda hemorrágica (AHLE), neuromielitis óptica (NMO) o vasculitis ${ }^{16} y$ así mismo, con formas menos típicas de leucoencefalopatía posterior reversible (PRES), relacionadas patogénicamente a hipertensión o al uso de antibióticos, quimioterápicos o inteferón ${ }^{17}$.

Se presentan tres casos de leucoencefalopatía tóxica fatal, de difícil identificación clínica. Serían los primeros casos descritos en relación al consumo de pasta base, y esta condición excepcional hizo sospechar en ellos la presencia de algún aditivo tóxico, motivo de su derivación a una autopsia médico legal en dos de ellos.

\section{Pacientes}

\section{Paciente 1}

Mujer de 31 años, consumidora de pasta base de cocaína. Consulta en urgencia después de tres días de cefalea persistente, disartria, dificultad para tragar y disminución de fuerzas del hemicuerpo derecho. Se constató hemiparesia derecha e imágenes hipodensas bihemisféricas en la tomografía axial computarizada (TAC). La paciente rechazó hospitalización. Dos semanas después es traída por familiares por acentuación de los síntomas, alucinaciones visuales y compromiso de conciencia. Ingresó desorientada, disártrica, con hemiparesia derecha, fondo de ojo normal. Líquido cefalorraquídeo, hemograma, creatinina, glicemia, nitrógeno ureico y electrolitos plasmáticos normales. Las serologías para virus herpes 1, 2 y 6, virus de la inmunodeficiencia humana (VIH) y citomegalovirus fueron negativas, así como para toxoplasma y Mycoplasma. Dos días después febril $39^{\circ} \mathrm{C}$, desaturando a $77 \%$, se identificó neumonía aspirativa. La resonancia magnética (RM) cerebral mostró múltiples lesiones hiperintensas en T2 y FLAIR que captaban contraste parcialmente (Figura 1). Recuperada de la neumonía, adquiría vigilancia espontanea, dirigía la mirada y obedecía órdenes simples, sin embargo, al compromiso motor en extremidades derechas se agregó paresia de la extremidad superior izquierda, hiperreflexia generalizada y Babinski bilateral. En el electroencefalograma se observó lentitud delta difusa, sin reactividad a la foto-estimulación. Se mantuvo somnolienta, las paresias evolucionaron a plejias una semana después. Se decide tratar como ADEM, se inician bolos de $1 \mathrm{~g}$ de metilprednisolona. Aparece trismo intermitente, mantiene los ojos abiertos con respuesta palpebral a la amenaza, sin establecer contacto. Dos días después se administra segundo bolo de metilprednisolona, reaparece la fiebre $y$ fallece.

\section{Paciente 2}

Mujer obesa de 31 años, consumidora habitual de cocaína y pasta base. Inicia su enfermedad con cefalea y vómitos, secuencialmente dificultad motora de extremidades derechas y disartria, estado confusional y somnolencia invencible. Después de tres semanas de comenzada la enfermedad ingresa en coma reactivo, localizaba estímulos, afebril, sin signos meníngeos, isocórica con pupilas reactivas, hemiparesia derecha, reflejos osteotendíneos exaltados y Babinski. Fondo de ojo normal. Sin otros hallazgos en el examen general. TAC de cerebro con múltiples imágenes hipodensas en substancia blanca. Hemograma, líquido cefalorraquídeo, creatinina, glicemia, protrombina y electrolitos plasmáticos normales. Anticuerpos antinucleares y ANCA no reactivos, VIH negativo. Electroencefalograma muestra actividad lenta simétrica. Dos días después, presenta fiebre por neumonía confirmada radiológicamente. La RM de cerebro (FLAIR, T2), mostró imágenes hiperintensas bilaterales de la substancia blanca cerebral, cerebelo y tronco cerebral (Figura 2). Se inician bolos de $1 \mathrm{~g}$ de metilprednisolona. Se observa mayor reactividad, dos días después se aplica segundo bolo. Presenta crisis febril sobre $39^{\circ} \mathrm{C}$, y cae en coma profundo. Fallece al día siguiente y se practica autopsia médico-legal. 

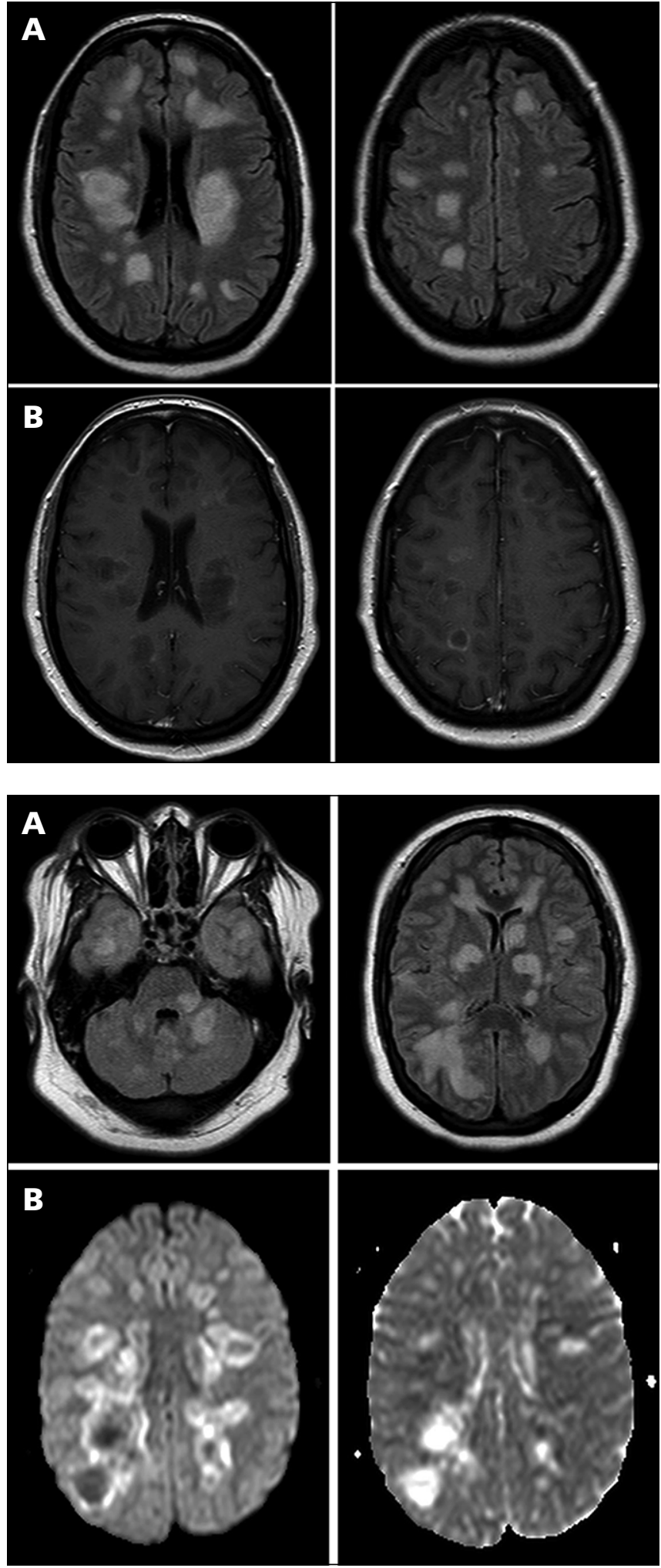

Figura 1. Caso $N^{\circ} 1(05 / 04 / 2013)$. Resonancia Magnética: A) En secuencia FLAIR se observan múltiples imágenes hiperintensas distribuidas en el centro semioval de ambos hemisferios cerebrales, que parecen respetar las fibras en $U$; B) Algunas de las lesiones muestran captación del medio de contraste en su periferia, que sugieren una alteración de la barrera hematoencefálica, o una reacción perilesional.

Figura 2. Caso $N^{\circ} 2(08 / 04 / 2014)$. Resonancia Magnética: A) En secuencia FLAIR se observan imágenes hiperintensas en el centro semioval, de ambas regiones frontales en áreas periventriculares y en ambos territorios parietooccipitales, que predominan en el lado derecho, también en la substancia blanca de los núcleos basales, del cerebelo y del pedúnculo cerebeloso izquierdo; B) En secuencias DWI/ADC se observa restricción en la difusión en las lesiones del centro semioval. 


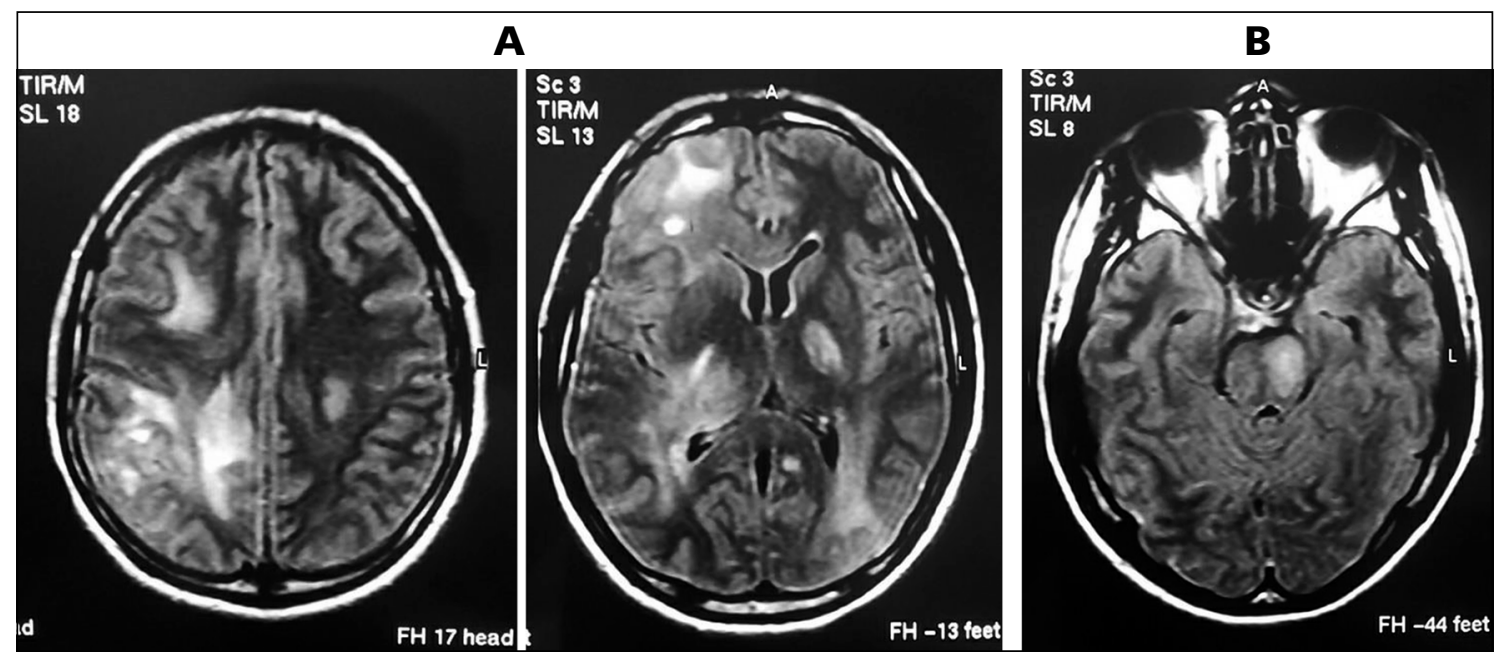

Figura 3. Caso $N^{\circ} 3(02 / 06 / 2014)$. Resonancia Magnética: A) En secuencia FLAIR se observan distintas áreas de hiperintensidad del centro semioval que tienen mayor expresión en las regiones frontoparietal derecha y occipitoparietal izquierda, que parecen respetar las fibras en $U$. También se observa hiperintensidad del pico del cuerpo calloso y de ambas cápsulas internas; B) En secuencia FLAIR se ven cambios de intensidad de toda la protuberancia, aunque se compromete especialmente el lado izquierdo del puente.

\section{Paciente 3}

Hombre de 19 años, consumidor circunstancial de marihuana y pasta base de cocaína. Consulta en Ovalle por cefalea persistente y desarrollo de déficit motor de extremidades derechas, compromiso de la visión y desequilibrio de la marcha. Ingresa orientado, disártrico, con hemiparesia derecha y signos cerebelosos bilaterales. Examen general y de laboratorio, líquido cefalorraquídeo y TAC de cerebro normales, fue dado de alta sin diagnóstico. Tres semanas después ingresa al Hospital del Salvador, afebril, sin signos meníngeos, comprometido de conciencia, con lenguaje incomprensible y fondo de ojo normal. La ausencia de respuestas a la amenaza hicieron sospechar amaurosis. También con tetraparesia, reflejos exaltados, Babinski bilateral. Ocasionales clonías rítmicas de la extremidad superior derecha. Exámenes de laboratorio y líquido cefalorraquídeo son normales, Proteína $\mathrm{C}$ reactiva 0,5 . La serología del virus de inmunodeficiencia, Epstein-Barr, herpes 1, 2 y HTLV-1 fueron no reactiva. RM cerebral, (T2 y FLAIR), hiperintensidad de áreas subcorticales frontoparietales derechas y parietooccipitales, hiperintensidad de la protuberancia mayor a izquierda (Figura 3). Se inicia terapia con bolos de metilprednisolona por enfermedad desmielinizante subaguda. Dos días después evoluciona con dificultad respiratoria, cuadro pulmonar agudo, cae en coma y fallece. Autopsia médico-legal.

\section{Comentario}

Se comentan tres pacientes con leucoencefalopatía tóxica fatal por consumo de pasta base de cocaína, que clínica e imagenológicamente son semejantes a lo descrito en la limitada literatura médica del tema ${ }^{2-6}$.

El análisis clínico de estos pacientes, permitió vislumbrar una secuencia en el desarrollo de la enfermedad que orienta hacia la causa tóxica, siempre elusiva cuando se carece del antecedente. En todos se aprecia latencia entre el uso del estupefaciente y el comienzo de la enfermedad, que se inicia con cefalea persistente seguida por la instalación de paresias, disartria, signos cerebelosos, alteraciones visuales y progresivo compromiso de conciencia, que luego de semanas llega al coma y fallecimiento. La enfermedad tiene un perfil encefalopático progresivo y la RM (T2, FLAIR) muestra imágenes hiperintensas difusas o multifocales en el centro oval, bihemisféricas, 
con eventual compromiso de tronco y cerebe$\mathrm{lo}^{8,11}$. El líquido cefalorraquídeo es normal y no se observan alteraciones biológicas generales, ni de otros parámetros clínicos. No difieren de los casos de encefalopatía tóxica descritos por el uso de cocaína ${ }^{4,7,8}$.

Las denominaciones de estos cuadros como leucoencefalopatía tóxica y leucoencefalopatía espongiforme ${ }^{18}$, se justifican porque incluyen conceptos esenciales de la enfermedad. Lo de tóxico se refiere tanto a la causa, como al daño del transporte axoplásmico en axones del centro oval, donde el aporte trófico de axones sanos resulta indispensables a los oligodendrocitos para mantener la mielinización. Sin embargo, la alteración del transporte axoplásmico no limita inicialmente la trasmisión eléctrica de esos axones, postergando la expresión clínica a la aparición de cambios del entorno tisular y de la mielina, definiendo las clásicas latencias que acompañan a las intoxicaciones y procesos degenerativos axonales ${ }^{19}$. El concepto espongiforme se refiere al modo como se afectaría la substancia blanca, con vacuolización de las vainas de mielina y variables grados de desmielinización o necrosis. Condición descrita en otras axonopatías subagudas como la mielopatía espongiforme por déficits de B6 o la intoxicación por monóxido de carbono $^{20}$, que en la leucoencefalopatía tóxica conlleva degeneración axonal ${ }^{10}$. Por ello llama la atención la leucoencefalopatía tóxica reversible, así como el caso de leucoencefalopatía tóxica recidivante, que parecen sugerir una interpretación o mecanismo patogénico distinto al de las leucoencefalopatías tóxicas fatales ${ }^{21,22}$.

El uso de bolos de metilprednisolona no benefició a estos enfermos. No se han establecido esquemas terapéuticos para su manejo, salvo medidas generales de neuroprotección y el uso de antioxidantes por el aumento de lactato ${ }^{13,23}$. Finalmente es necesario referirse a los aditivos tóxicos que suelen asociarse a la cocaína, como el levamisol droga primariamente antihelmíntica, luego antimitótico, ahora un atractivo aditivo para la cocaína debido a sus efectos sobre la recaptación noradrenérgica, capacidad para formar compuestos anfetamino-símiles, impulsar un incremento en la expresión de opiodes endógenos y aumentar la concentración de dopamina. Para algunos investigadores, los aditivos serían los verdaderos causantes de las leucoencefalopatías tóxicas fatales que se han atribuido a la cocaína ${ }^{4,24}$ como probablemente aconteció con las encefalopatías aquí descritas.

\section{Referencias}

1. Neiman J, Haapeniemi HM, Hillbom M. Neurological complications of drug abuse: pathophysiological mechanisms. Eur J Neurol 2000; 7 (6): 595-606.

2. Wolters EC, Van Wijngaarden GK, Stam FC, Rengelink H, Lousberg RJ. Leukoencephalopathy after inhaling "heroin" pyrolysate. Lancet 1982; 2: 1233-7.

3. Blasel S, Hattingen E, Adelman M, Nichtwei M, Zanella F, Weidauer S. Toxic leukoencephalopathy after heroin abuse without heroin vapor inhalation. MR imaging and clinical feature in three patients. Clin Neuroradiol 2010; 20 (1): 48-53.

4. Blanc PD, Chin C, Lynch KL. Multifocal inflammatory leukoencephalopathy associated with cocaine abuse: is levamisole responsible? Clin Toxicol (Phila) 2012; 50 (6): 534-5.

5. Salgado R. Methadone-Induced Toxic Leukoencephalopathy: MR Imaging and MR Proton Spectroscopy Findings. Ame J. Neuroradiol 2009; 31: 565-6.

6. Sacks J, Ray MJ, Williams S. Opatowsky MJ. Fatal toxic leukoencephalopathy, secondary to overdose of a new psychoactive designer drug 2C-E ("Europa"). Proc (Bayl Univ Med Cent) 2012; 25 (4): 374-6.

7. Filley CM, Kleinschmidt-Demasters BK. Toxic Leukoencephalopathy. N Engl J Med 2001; 345: 425-32.

8. Jeffrey H, Andrews G, Vertinskyt, Heran M, Keogh C. Chasing the dragon - Imaging of heroin inhalation Leukoencephalopathy. Journal De L Association Canadienne Des Radiologistes 2013; 56 (4): 199-203.

9. Offiah C, Hall E. Heroin-induced leukoencephalopathy: characterization using MRI, diffusion-weighted imaging, and MR spectroscopy. Clinical Radiology 2008; 63 (2): 146-52.

10. Ryana, Molloyfm, Farrell MA, Hutchinson M. Fatal toxic leukoencephalopathy: clinical, radiological, and necropsy findings in two patients. J Neurol Neurosurg Psychiatry 2005; 76: 1014-6.

11. Sharma P, Eesa M, Scott JN. Toxic and acquired metabolic encephalopathies: MRI appearance. Am J Roentgenol 2009; 193 (3): 879-86.

12. Vella S, Kreis R, Lovblad KO, Steinlin M. Acute leukoencephalopathy after inhalation of a single dose of heroin. Neuropediatrics 2003; 34: 100-4.

13. Kondziella D, Danielsen ER, Arlien-Soeborg P. Fatal encephalopathy after an isolated overdose of cocaine. BMJ Case Rep 2009; 2009: bcr06.2009.2003. 
14. Santis R, Hidalgo CG, Hayden V, Anselmo E, Rodríguez J, Cartajena F, et al. Consumo de sustancias y conductas de riesgo en consumidores de pasta base de cocaína y clorhidrato de cocaína no consultantes a servicios de rehabilitación. Rev Med Chile 2007; 135: 45-53.

15. Espinoza LR, Pérez AR. Cocaine-induced vasculitis: clinical and immunological spectrum. Curr Rheumatol Rep 2012; 14 (6): 532-8.

16. Menge T, Hemmer B, Nessler S, Wiendl H, Neuhaus $\mathrm{O}$, Hartung HP, et al. Acute disseminated encephalomyelitis: an update. Arch Neurol 2005; 62 (11): 1673-80.

17. López-García F, Amorós-Martínez F, Sempere AP. Síndrome de leucoencefalopatía posterior reversible. Rev Neurol 2004; 38 (3): 261-6.

18. Chen CY, Lee KW, Lee CC, Chin SC, Chung HW, Zimmerman RA. Heroin-induced spongiform leukoencephalopathy: value of diffusion MR imaging. J Comput Assist Tomogr 2000; 24: 735-7.

19. Morfini GA, Burns M, Binder LI, Kanaan NM, Lapointe
N, Bosco DA, et al. Axonal transport defects in neurodegenerative diseases. Journal of Neuroscience 2009; 29 (41): 12776-86.

20. Lapresle J, Fardeau M. Les leuco-encéphalopathies de l'intoxication oxycarbonée. Acta Neuropathol 1966; 6: 327-48.

21. Bianco F, Lacovelli E, Tinelli E, Lepre C, Pauri F. Recurrent leukoencephalopathy in a cocaine abuser. Neurotoxicology 2011; 32 (4): 410-2.

22. González-Duarte A, Williams R. Cocaine-Induced Recurrent Leukoencephalopathy Neuroradiol J. 2013; 26 (5): 511-3.

23. Kriegstein AR, Shungu DC, Millar WS, Armitage BA, Brust JC, Chillrud S, et al. Leukoencephalopathy and raised brain lactate from heroin vapor inhalation ("chasing the dragon”). Neurology 1999; 53: 1765-73.

24. Larocque A, Hoffman RS. Levamisole in cocaine: unexpected news from an old acquaintance. Clin Toxicol (Phila) 2012; 50 (4): 231-41. 